\title{
Correlation of FOXL2 with Inhibin and Calretinin in the Diagnosis of Ovarian Sex Cord Stromal Tumors
}

\author{
Ruchi RATHORE, Deepshikha ARORA, Sarla AGARWAL, Sonal SHARMA
}

Department of Pathology, University College of Medical Sciences, NEW DELHI, INDIA

\begin{abstract}
Objective: Alpha-inhibin and calretinin have been traditionally used as immunomarkers for sex cord stromal tumors. However, the variation in their immunoreactivity and their lack of specificity for sex cord stromal tumor makes the search for a more sensitive and specific immunohistochemical marker essential in routine diagnosis of sex cord stromal tumor. This study was conducted to correlate the diagnostic utility of FOXL2 with inhibin and calretinin in the diagnosis of sex cord stromal tumors of ovary.
\end{abstract}

Material and Method: The study was conducted in the department of pathology. 31 cases of sex cord tumors received in past eight years (2002-2010) were included in this study. Immunostaining for inhibin, calretinin and FOXL2 was performed and compared on the basis of staining intensity and percentage positivity on all the cases.

Results: Calretinin was found to be positive in 29/31 sex cord stromal tumors with variable intensities and was negative in two cases of sex cord stromal tumors, inhibin was positive in $28 / 31$ and only three cases had no cytoplasmic staining. All the 31 cases included in this study were positive for FOXL2 with variable staining intensities and percentage positivity. Ten cases of each surface epithelial and germ cell tumors were also negatively stained with FOXL2.

Conclusion: In contrast to inhibin and calretinin, FOXL2 had a sensitivity and specificity of $100 \%$ for all the cases of sex cord stromal tumors included in this study.

Key Words: FOXL2, Inhibin, Calretinin, Ovarian neoplasms, Sex cord stromal tumor

\section{INTRODUCTION}

Sex cord stromal tumors (SCST) constitute $8 \%$ of all the ovarian neoplasms comprising those that contain granulosa cells, theca cells, and their luteinized derivatives, Sertoli cells, Leydig cells and fibroblast of gonadal stromal origin singly or in various combinations with varying degrees of differentiation (1). These tumors as known for their hormonal activity are slow growing tumors and have a tendency of late recurrence. Since the patients are often young and most tumors are unilateral, accurate diagnosis is necessary for proper treatment and maintenance of fertility where desirable.

Although the mainstay for diagnosing these SCST remains gross and microscopic features, the presence of diverse morphological variations makes the use of immunohistochemistry essential in their diagnosis. The widely varied appearance of SCST and the fact that some of them are uncommon can lead to difficulties in their diagnosis. Some of them may show atypical or

(Turk Patoloji Derg 2017, 33:121-128)

Received : 29.12.2014 Accepted : 25.11.2016 unconventional microscopic patterns and, therefore, morphology alone may not be reliable for an unequivocal classification. In these cases, immunohistochemistry can be of value. Alpha-inhibin (2-6) and calretinin $(7,8)$ have been traditionally used as immunomarkers of SCST. However due to the variation in their immunoreactivity and a lack of specificity for SCST, the search for a more sensitive and specific immunohistochemical marker becomes essential in routine diagnosis of SCST.

In the recent past, FOXL2 mutations have been consistently found in adult granulosa cell tumors $(9,10)$. Currently there are increasing numbers of studies eliciting the role of FOXL2 in the diagnosis of adult granulosa cell tumors but there is paucity of literature on its diagnostic utility in comparison to inhibin and calretinin in the diagnosis of the entire spectrum of SCST of the ovary. The aim of this study was to evaluate the role of FOXL2 and its correlation with inhibin and calretinin in the diagnosis of entire spectrum of SCST.

Correspondence: Sonal SHARMA

University College of Medical Sciences, Department of Pathology,

NEW DELHI, INDIA

E-mail: sonald76@gmail.comＰhone: +9198100 44303 


\section{MATERIAL and METHODS}

\section{Case Selection}

The study was conducted in the department of pathology of our institute. Thirty-one cases of SCST received in past eight years (2002-2010) were included in this study. These consisted of 17 adult granulosa cell tumors, 1 juvenile granulosa cell tumor, 7 fibrothecoma, 1 fibroma, 1 fibrosarcoma, 1 SCST of uncertain histogenesis, 1 poorly differentiated tumor possibly granulosa cell tumor and 2 cases of Sertoli-Leydig cell tumor. For all the cases, Hematoxylin and Eosin (H\&E) stained slides were retrieved from archives and reviewed by expert pathologists. Ten cases each of surface epithelial and germ cell tumors were also included in the study for FOXL2 staining.

\section{Immunohistochemistry}

The blocks were selected for immunohistochemical demonstration of inhibin, calretinin and FOXL2. Then 3-4 micrometer thick sections were taken from each block on poly-L-lysine-coated slides. These were stained with monoclonal antibody against a subunit of inhibin, antibody to calretinin and polyclonal antibody to C-terminal hexadecapeptide of the human FOXL2 protein respectively using the avidin biotin method. The primary antibody for FOXL2 used in this study was polyclonal FOXL2-antiserum (1:200; Imgenex, San Diego, CA, USA). For calretinin and inhibin the primary antibodies used were monoclonal anticalretinin (RTU, Spring Biosciences, CA, USA) and monoclonal anti-inhibin (1:50; Spring biosciences, CA, USA) respectively. Serial dilutions of antibody were tested to avoid background staining and to find optimal staining before the entire series was processed. Sections from normal ovary with graffian follicles were used as positive control. For negative controls, primary antibody was replaced by TRIS buffer.

\section{Immunostaining Analysis}

The slides were examined at 40x magnification. Positive reaction was characterized by cytoplasmic (inhibin), nuclear and cytoplasmic (calretinin), nuclear (FOXL2) staining showing variable intensities with the distribution of staining approximated for variable intensity levels. The presence of any nuclear staining of FOXL2, regardless of intensity or focality, was considered to be positive.

\section{Statistical Analysis}

Sensitivity, specificity, negative predictive value, and positive predictive value for inhibin, calretinin and FOXL2 were determined taking histopathology as the gold standard. Ten cases each of malignant surface epithelial tumors and germ cell tumors were included in this study to determine the specificity of antibodies for SCST. The exact binomial method (Clopper-Pearson) was applied to calculate the confidence interval of diagnostic indices. SPSS version 17-statistic software was used for data analysis

\section{Comparison of Immunostaining for FOXL2, Inhibin and Calretinin}

Immunostaining for FOXL2, inhibin and calretinin were compared on the basis of staining intensity and percentage positivity in all the cases. The staining intensity was graded as -weak (1+), moderate (2+), strong (3+). The percentage of tumor cells labeled by FOXL2, inhibin and calretinin were semiquantitatively scored as $<5 \%$ (negative), $5-25 \%$ (1+), 26-50\% (2+), 51-75\% (3+), >75\% (4+).

\section{RESULTS}

\section{Inhibin Immunoanalysis}

Inhibin was positive in the majority of the SCST i.e. 28/31 and only 3 cases had no cytoplasmic staining (Table I). Of all negatively stained tumors, two were granulosa cell tumors which included a cystic granulosa cell tumor and the other was a granulosa cell tumor with postchemotherapy changes (bizarre cells), and the remaining case was a SCST of uncertain histogenesis (Figure 1A-D) (Table I).

Taking H\&E stained sections as the gold standard, the sensitivity of inhibin was $90.3 \%$ and the specificity was $100 \%$ for SCST. The positive predictive value for inhibin in our study was $100 \%$ and the negative predictive value was $87.0 \%$.

\section{Calretinin Immunoanalysis}

Calretinin was found to be positive in 29/31 SCST with variable intensities and was negative in 2 cases of SCST including 1 case of fibrothecoma and the other of fibrosarcoma (Table I). Both the above stated cases were also found to be negative, when the percentage positivity of all the 31 cases was seen. The remaining 29/31 cases had variable staining intensities ranging from $1(+)$ to $4(+)$ (Table I).

The sensitivity of calretinin in this study was $93.5 \%$ while the specificity was $100 \%$. The negative predictive value of calretinin for this study was $90.9 \%$ and the positive predictive value was $100 \%$. H\&E stained sections were taken as the gold standard for the analysis. (Figure 1A-D)

\section{FOXL2 Immunoanalysis}

Thirty-one cases of SCST were stained using a polyclonal antibody against FOXL2, which is a nuclear protein. Ten cases each of surface epithelial and germ cell tumors were 
Table I: Inhibin, calretinin and FOXL2 immunoanalysis for sex cord stromal tumors.

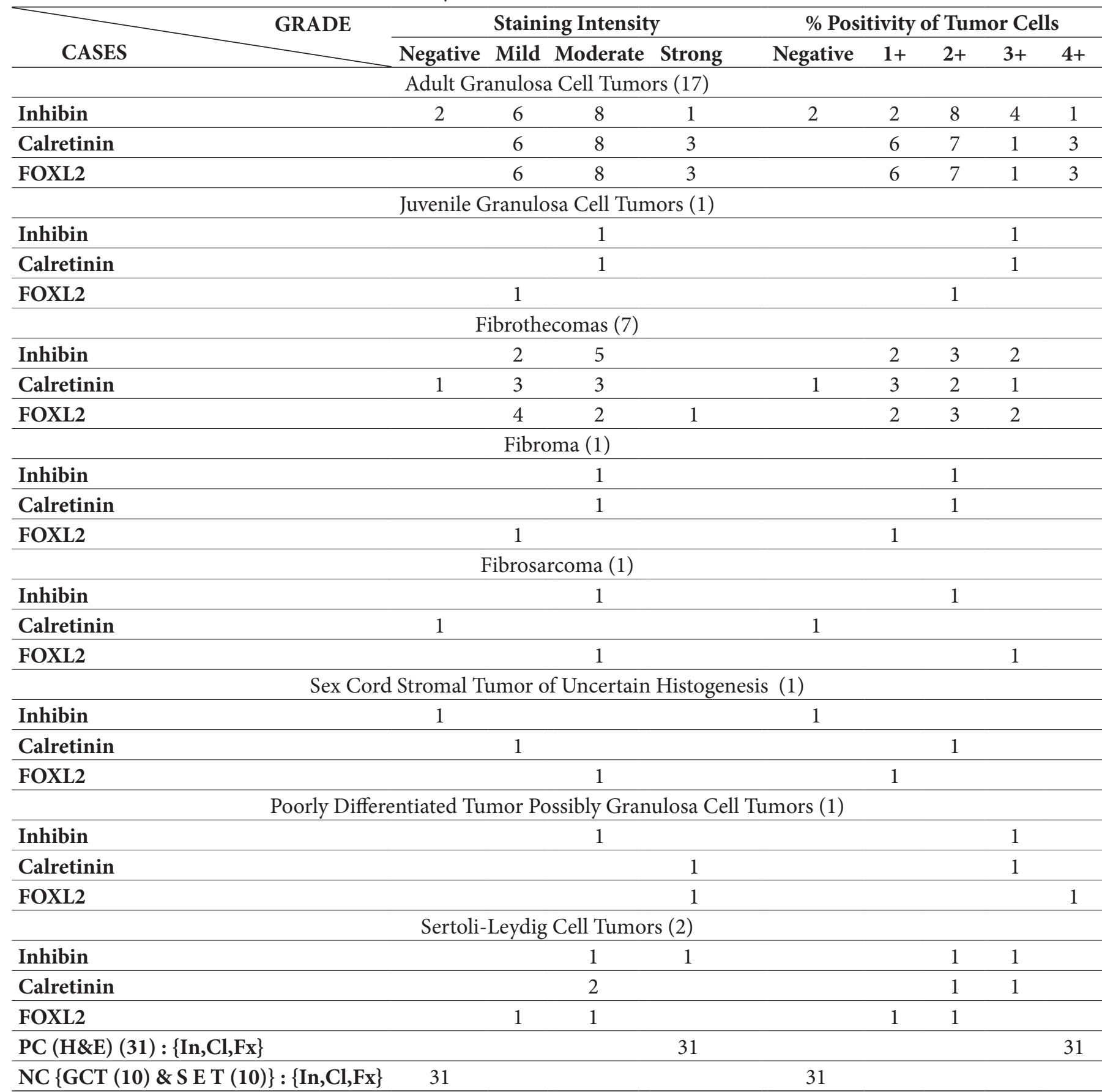

PC : Positive Control, NC : Negative Control, H\&E :Hematoxylin and Eosin, GCT: Germ Cell Tumor, SET: Surface Epithelial Tumor, In: Inhibin, Cl: Calretinin, Fx : FOXL2.

also stained with FOXL2. All negative controls as well as surface epithelial and germ cell tumors were negative. Positive control had a nuclear pattern of staining in the granulosa cells of normal ovary (Figure 1A-D).

FOXL2 was positive with variable staining intensities and percentage positivity in all the cases included in this study. While 16/31 SCST had mild intensity of staining, $6 / 31$ had strong staining intensity and 9/31 had moderate intensity of staining. Tumors, which were strongly positive included 4/17 adult granulosa cell tumors and $1 / 7$ fibrothecomas. One tumor which was signed out as poorly differentiated tumor possibly granulosa cell tumor 

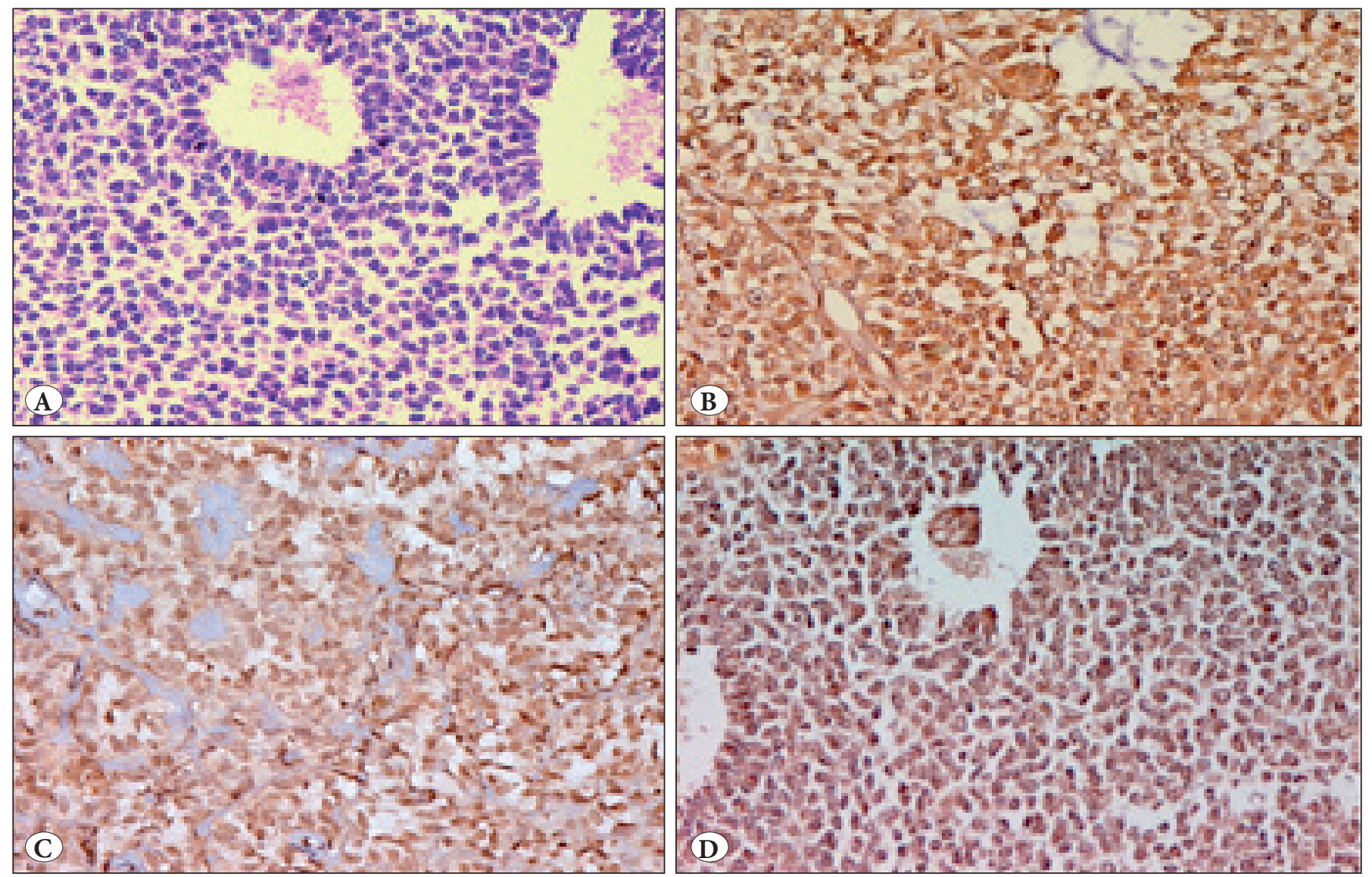

Figure 1: Granulosa cell tumor: A) H\&E staining section (H\&E; x400) B) Cytoplasmic positivity for inhibin (Inhibin; x400) C) Nuclear and cytoplasmic positivity for calretinin (Calretinin; x400). D) Nuclear positivity for FOXL2 (FOXL2; x400).

and was positive for inhibin and calretinin also had strong intensity of staining with FOXL2 (Figure 2A,B). Tumors showing moderate intensity of staining included $4 / 17$ adult granulosa cell tumor, 2/7 cases of fibrothecoma, 1/1 of fibrosarcoma and 1/2 Setoli-Leydig cell tumor. 1/1 SCST of uncertain histogenesis included in this study was also moderately positive for FOXL2 (Table I). The remaining cases, including 9/17 adult granulosa cell tumors, $1 / 1$ case of juvenile granulosa cell tumor, 4/7 fibrothecomas, 1/1 fibroma and 1/2 Sertoli-Leydig cell tumors, were mildly positive for FOXL2 (Table I).

Comparing the percentage positivity for all the 31 cases of SCST, it was seen that of the three cases having $4(+)$ percentage positivity, 2 were granulosa cell tumors with diffuse microscopic patterns and one was a poorly differentiated tumor. $8 / 31$ cases that had $3(+)$ positivity, which included $5 / 17$ adult granulosa cell tumors followed by 1/7 fibrothecomas, 1/1 fibrosarcoma and 1 case of SertoliLeydig cell tumors. The only case of juvenile granulosa cell tumor included in the study had $2(+)$ percentage positivity while SCST of uncertain histogenesis had 1(+) percentage positivity. 3/7 fibrothecomas had $1(+)$ and $3 / 7$ had $2(+)$ percentage positivity respectively (Table I).

Taking H\&E sections as the gold standard, the sensitivity and specificity of FOXL2 was $100 \%$ and negative predictive values as well as positive predictive value were also $100 \%$ in our study. Moreover, ten cases each of surface epithelial tumors and germ cell tumors were negative for FOXL2.

\section{Comparison of FOXL2, Inhibin and Calretinin}

In contrast to inhibin and calretinin, FOXL2 had a sensitivity and specificity of $100 \%$ for all the cases of SCST included in the study (Table II).

\section{DISCUSSION}

Inhibin is a dimeric $32 \mathrm{KDa}$ peptide hormone composed of an $\alpha$ subunit and a $\beta$ subunit. Apart from being produced normally by granulosa cells and testicular Sertoli cells, its extragonadal expression in the placenta, adrenal gland, pituitary gland and liver has also been demonstrated in various studies (11-16). Most studies have shown that inhibin is expressed in nearly all granulosa cell tumors, 

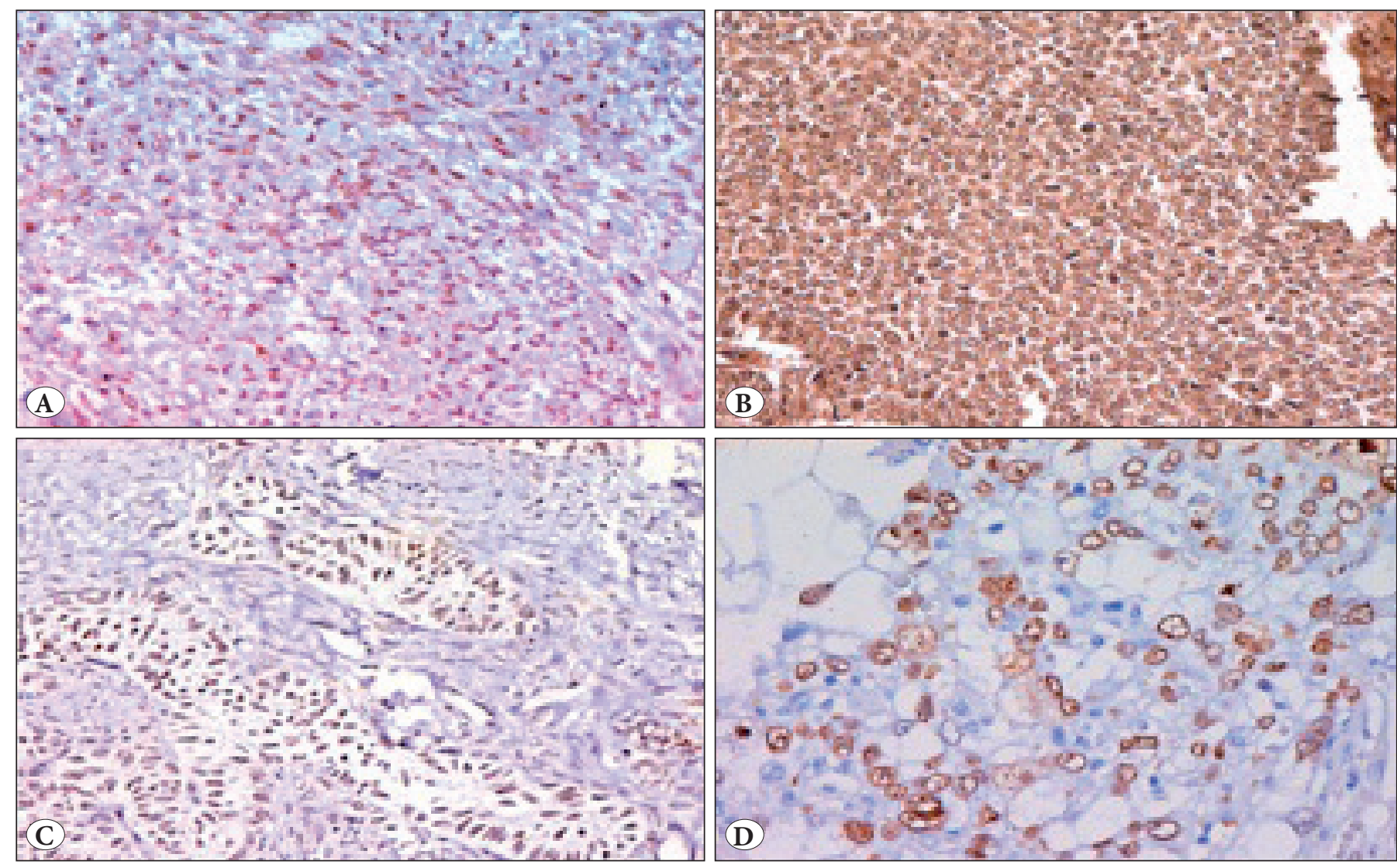

Figure 2: A) Nuclear FOXL2 staining in fibrothecoma (Immunohistochemistry; x400). B) Adult Granulosa Cell Tumor (FOXL2; x400). C) Sertoli-Leydig cell tumor (FOXL2; x400). D) Juvenile granulosa cell tumor (FOXL2; x400).

Table II: Comparison of immunohistochemical staining sensitivity, specificity, negative predictive value and positive predictive value of inhibin, calretinin and FOXL2

\begin{tabular}{lccccc}
\hline \multicolumn{5}{c}{ Comparison of Inhibin, Calretinin and FOXL2 } \\
\hline Immunostain & +ve Cases & Sensitivity (\%) & Specificity (\%) & NPV (\%) & PPV (\%) \\
\hline Inhibin (CI) & $28 / 31$ & $90.3(74.2-98)$ & $100(83.2-100)$ & $87.0(66.4-97.2)$ & $100(87.7-100)$ \\
\hline Calretinin (CI) & $29 / 31$ & $93.5(78.6-99.2)$ & $100(83.2-100)$ & $90.9(70.8-98.9)$ & $100(88.1-100)$ \\
\hline FOXL2 (CI) & $31 / 31$ & $100(88.8-100)$ & $100(83.2-100)$ & $100(83.2-100)$ & $100(88.8-100)$ \\
\hline
\end{tabular}

NPV: Negative Predictive Value, PPV: Positive Predictive Value, CI: Confidence Interval

juvenile and adult types, most Sertoli and Leydig cell tumors, SCST with annular tubules, gynandroblastomas, and steroid cell tumors (17,18-21). However, Matias-Guiu et al. demonstrated that it is less frequently expressed in fibromas, fibrothecomas and unclassified SCST and is absent in fibrosarcoma (17). In our study it was seen that inhibin was positive in the majority of the SCST i.e. $28 / 31$ (90.3\%) and only 3 cases had no cytoplasmic staining. As opposed to the previous studies, all 7/7 cases of fibrothecoma and $1 / 1$ cases of fibroma (moderate intensity) were positive for inhibin. In fact, a single case of fibrosarcoma included in our study demonstrated moderate intensity of staining with inhibin. However, in accordance with the described literature, the only case of SCST of uncertain histogenesis included in our study was negative for inhibin immunoreactivity.

Calretinin, a 29-kd calcium-binding protein, has been shown in human ovarian surface epithelial cells, theca interna cells, stromal cells, hilar cells, and certain types of ovarian SCST by various research groups (22-25). Calretinin, initially used for the diagnosis of mesothelioma, has been shown to be highly sensitive but a less specific marker than inhibin for SCST of the ovary. In studies conducted by Movahedi et al. and Shah et al., it was seen that calretinin has a sensitivity of $97 \%$ and specificity of $85 \%$ (except in granulosa cell tumors with extensive luteinization, which less frequently express calretinin) 
compared with inhibin having $71 \%$ sensitivity and $97 \%$ specificity $(26,27)$. However, the sensitivity of calretinin in this study was $93.5 \%$ while the specificity was $100 \%$. The negative predictive value of calretinin for this study was $90.9 \%$ and the positive predictive value was $100 \%$.

In contrast to inhibin, calretinin is more frequently expressed in epithelial ovarian tumors including serous, mucinous, clear cell, and endometroid carcinomas (as many as $22 \%$ of cases in one series) and is therefore less reliable in the differential diagnosis of SCST and endometroid carcinoma $(20,26)$. It has been noted in various studies that fibromas are frequently positive for calretinin and negative for inhibin and the sole use of calretinin in this setting is more discriminatory $(26,28,29)$. In our study it was seen that in the single case of SCST of uncertain histogenesis where inhibin was found to be negative, calretinin staining gave a $1(+)$ percentage positivity in cells whereas the only case of a poorly differentiated tumor possibly granulosa cell tumor on morphology had strong positivity for both inhibin as well as calretinin. Moreover, it was seen that in the case of cystic granulosa cell tumor and granulosa cell tumor with postchemotherapy changes where inhibin was negative, calretinin was strongly positive. Our study supports that calretinin is more sensitive than inhibin for the diagnosis of SCST as described in the literature.

FOXL2, a forkhead transcription factor is a key factor in proper differentiation of granulosa cells during folliculogenesis and its expression persists in the ovary after birth (30). Shah et al. identified a single recurrent somatic, missense mutation in FOXL2 (C402G), which was present in almost all morphologically identified adult type granulosa cell tumours (9). Kalfa et al. studied the underexpression of FOXL2 in juvenile ovarian granulosa cell tumors with an aggressive pattern of progression and it thus may be a prognostic factor for these tumors (31). Rosario et al. concluded that FOXL2 mutations target the deregulation of TGF- $\beta$ signaling genes, a key antiproliferative pathway in the pathogenesis of adult-type GCTs (32). However, its exact role in the pathogenesis of these tumors is still under evaluation. FOXL2 immunostaining gives a nuclear pattern of staining due to the nuclear location of FOXL2 protein, a transcription factor antibody.

Recently a study conducted by Osama et al. demonstrated that FOXL2 is a robust immunohistochemical marker for SCST that works in formalin-fixed, paraffin-embedded tissue sections and is highly expressed in both FOXL2mutant SCST and a subset of SCST without a (402C-G) mutation in FOXL2. FOXL2 immunostaining is both sensitive and highly specific for SCST, performing better than $\alpha$ inhibin and calretinin. A subset of SCST is typically negative for FOXL2 on immunostaining (retiform or poorly differentiated SLCT), but these tumors usually express $\alpha$ inhibin and/or calretinin. In most of the FOXL2 positive cases in this study, FOXL2 demonstrated a nuclear pattern of staining and stained a high proportion of tumor cells leading to easy interpretable staining (33).

A single study conducted by McCluggage et al. on the expression of FOXL2 in fibromas and its diagnostic utility as an adjunct in the differential diagnosis of diffuse granulosa cell tumors concluded that FOXL2 mutations are absent in ovarian fibromas in contrast to granulosa cell tumors and are thus a useful diagnostic adjunct in distinction from diffuse adult granulosa cell tumors (34).

In our study it was seen that all the cases including $100 \%$ of adult granulosa cell tumors, $100 \%$ of juvenile granulosa cell tumors, all the cases of fibrothecoma, fibrosarcoma, fibroma, SCST of uncertain histogenesis and poorly differentiated tumor possibly granulosa cell tumor on morphology were positive for FOXL2. McCluggage et al. detected no FOXL2 mutation in ovarian fibroma. The importance of detection of FOXL2 expression in ovarian fibroma is not clear because FOXL2 expression was detected in only one case in our study. This finding should be investigated in large case series and compared with FOXL2 mutation and expressions in the tumor (34). All the cases that were negative for inhibin or calretinin were positive for FOXL2 in our study. Taking H\&E sections as the gold standard, the sensitivity and specificity of FOXL2 was $100 \%$ and negative predictive values as well as positive predictive value were also $100 \%$ in our study. Though the pattern of immunoreactivity in our study was in accordance with the literature, the limited number of cases included in our study was a major setback in studying the role of FOXL2 in the whole range of SCST. No case of steroid cell tumor, Leydig cell tumor or female adnexal tumor of probable Wolffian origin and only a single case of fibroma in which FOXL2 has been shown to be negative in earlier studies was included in our study.

However, it was demonstrated that most cases of SCSTs were positive for FOXL2 as compared to inhibin or calretinin in this study. Our results also suggested that FOXL2 had a better percentage positivity of cells as compared to earlier well-established markers such as calretinin and inhibin. As only a limited number of cases were included in this study, the whole range of sex cord stromal tumors could not be evaluated for immunohistochemical analysis and further studies with a wider range of these tumors are required for the validation of our study. 
In conclusion, testing for FOXL2 immunoexpression can serve to distinguish between SCST and non-SCST. However, we acknowledge that the smaller number of cases included in our study was a major limitation and further validation with a larger number of cases is still required.

\section{CONFLICT of INTEREST}

No financial support of any form has been taken from any agency for this study.

\section{REFERENCES}

1. Mehta H, Trivedi P, Parikh B, Shukla K, Shah MJ. Clinicopathological prognostic factors of adult granulosa cell tumor of the ovary-a study of 37 cases. Indian J Pathol Microbiol. 2005;48:439-43.

2. Edwards BK, Brown ML, Wingo PA, Howe HL, Ward E, Ries LA, Schrag D, Jamison PM, Jemal A, Wu XC, Friedman C, Harlan L, Warren J, Anderson RN, Pickle LW. Annual report to the nation on the status of cancer, 1975-2002, featuring population-based trends in cancer treatment. J Natl Cancer Inst. 2005;97:1407-27.

3. Scully RE, Young RH, Clement PB. Tumors of ovary, maldeveloped gonads, fallopian tube and broad ligament. In: Atlas of Tumor Pathology, 3rd series, fascicle 23. Washington DC: Armed Forces Institute of Pathology. 1998.

4. Cathro HP, Stoler MH. The utility of calretinin, inhibin, and WT1 immunohistochemical staining in the differential diagnosis of ovarian tumors. Hum Pathol. 2005;36:195-201.

5. McCluggage WG, Maxwell P. Immunohistochemical staining for calretinin is useful in the diagnosis of ovarian sex cord-stroma tumours. Histopathology. 2001;38:403-8.

6. Ottolenghi C, Pelosi E, Tran J, Colombino M, Douglass E, Nedorezov T, Cao A, Forabosco A, Schlessinger D. Loss of Wnt4 and Foxl2 leads to female-to-male sex reversal extending to germ cells. Hum Mol Genet. 2007;16:2795-804.

7. Young RH, Clement PB, Scully RE: The Ovary. In: Sternberg S editor. Diagnostic Surgical Pathology. Philadelphia: Lippincott, Williams \& Wilkins, 1999;2307-94

8. Arora DS, Cooke IE, Ganesan TS, Ramsdale J, Manek S, Charnock FM. Immunohistochemical expression of inhibin/ activin subunits in epithelial and granulosa cell tumours of the ovary. J Pathol. 1974;181:413-8.

9. Shah SP, Köbel M, Senz J, Morin RD, Clarke BA, Wiegand KC Leung G, Zayed A, Mehl E, Kalloger SE, Sun M, Giuliany R, Yorida E, Jones S, Varhol R, Swenerton KD, Miller D, Clement PB, Crane C, Madore J, Provencher D, Leung P, DeFazio A, Khattra J, Turashvili G, Zhao Y, Zeng T, Glover JN, Vanderhyden B, Zhao C, Parkinson CA, Jimenez-Linan M, Bowtell DD, Mes-Masson AM, Brenton JD, Aparicio SA, Boyd N, Hirst M, Gilks CB, Marra M, Huntsman DG. Mutation of FOXL2 in granulosa-cell tumors of the ovary. N Engl J Med. 2009;360:2719-29.

10. Beysen D, Vandesompele J, Messiaen L, De Paepe A, De Baere E.The human FOXL2 mutation database. Hum Mutat. 2004;24:189-93.
11. McCluggage WG, Shanks JS, Whiteside C, Maxwell P, Banerjee SS, Biggart JD. Immunohistochemical study of testicular sex cord-stromal tumors, including staining with anti-inhibin antibody. Am J Surg Pathol. 1998;22:615-19.

12. Meunier H, Rivier C, Evans RM, Vale W. Gonadal and extragonadal expression of inhibin alpha, beta $\mathrm{A}$ and beta $\mathrm{B}$ subunits in various tissues predicts diverse functions. Proc Natl Acad Sci U S A. 1988;85:247-51.

13. Crawford RJ, Hammond VE, Evans BA, Coghlan JP, Haralambidis J, Hudson B, Penschow JD, Richards RI, Tregear GW. Alphainhibin gene expression occurs in the ovine adrenal cortex, and is regulated by adrenocorticotrophin. Mol Endocrinol. 1987;1:699706.

14. McCluggage WG, Burton J, Maxwell P, Sloan JM. Immunohistochemical staining of normal, hyperplastic and neoplastic adrenal cortex with a monoclonal antibody against alpha inhibin. J Clin Pathol. 1998;51:114-16.

15. McCluggage WG, Maxwell P, Patterson A, Sloan JM. Immunohistochemical staining of hepatocellular carcinoma with monoclonal antibody against inhibin. Histopathology. 1997;30:518-22.

16. McCluggage WG, Ashe P, McBride H, Maxwell P, Sloan JM. Localisation of the cellular expression of inhibin in trophoblastic tissue. Histopathology. 1998;32:252-6.

17. Matias-Guiu X, Pons C, Prat J. Müllerian inhibiting substance, alpha-inhibin, and CD99 expression in sex cord-stromal tumors and endometrioid ovarian carcinomas resembling sex cordstromal tumors. Hum Pathol. 1998;29:840-5.

18. Matias-Guiu X, Prat J. Alpha-inhibin immunostaining in diagnostic pathology. Adv Anat Pathol. 1998;5:263-7.

19. Zheng W, Senturk BZ, Parkash V. Inhibin immunohistochemical staining: A practical approach for the surgical pathologist in the diagnoses of ovarian sex cord-stromal tumors. Adv Anat Pathol. 2003;10:27-38.

20. McCluggage WG, Maxwell P, Sloan JM. Immunohistochemical staining of ovarian granulosa cell tumors with monoclonal antibody against inhibin. Hum Pathol. 1997;28:1034-8.

21. Kommoss F, Oliva E, Bhan AK, Young RH, Scully RE. Inhibin expression in ovarian tumors and tumor-like lesions: An immunohistochemical study. Mod Pathol. 1998;11:656-64.

22. Bertschy S, Genton CY, Gotzos V. Selective immunocytochemical localisation of calretinin in the human ovary. Histochem Cell Biol. 1998;109:59-66

23. Cao QJ, Jones JG, Li M. Expression of calretinin in human ovary, testis and ovarian sex cord-stromal tumors. Int J Gynecol Pathol. 2001;20:346-52.

24. Jones MW, Harri R, Dabbs DJ, Carter GJ. Immunohistochemical profile of steroid cell tumor of the ovary: A study of 14 cases and a review of the literature. Int J Gynecol Pathol. 2010;29:315-20.

25. Fine SW, Li M.Expression of calretinin and the alpha-subunit of inhibin in granular cell tumors. Am J Clin Pathol. 2003;119:25964.

26. Movahedi-Lankarani S, Kurman RJ. Calretinin, a more sensitive but less specific marker than alpha-inhibin for ovarian sex cordstromal neoplasms: An immunohistochemical study of 215 cases. Am J Surg Pathol. 2002;26:1477-83. 
27. Shah VI, Freites ON, Maxwell P, McCluggage WG. Inhibin is more specific than calretinin as an immunohistochemical marker for differentiating sarcomatoid granulosa cell tumour of the ovary from other spindle cell neoplasms. J Clin Pathol. 2003;56:221-4.

28. Baker PM, Oliva E. Immunohistochemistry as a tool in the differential diagnosis of ovarian tumors: An update. Int J Gynecol Pathol. 2005;24:39-55.

29. Deavers MT, Malpica A, Liu J, Broaddus R, Silva EG. Ovarian sex cord-stromal tumors: An immunohistochemical study including a comparison of calretinin and inhibin. Mod Pathol. 2003;16:584-90.

30. Cocquet J, Pailhoux E, Jaubert F, Servel N, Xia X, Pannetier M. Evolution and expression of FOXL2. J Med Genet. 2002;39:91621.
31. Kalfa N, Philibert P, Patte C, Ecochard A, Duvillard P, Baldet P, Jaubert F, Fellous M, Sultan C. Extinction of FOXL2 expression in aggressive ovarian granulosa cell tumors in children. Fertil Steril. 2007;87:896-901.

32. Rosario R1, Araki H, Print CG, Shelling AN. The transcriptional targets of mutant FOXL2 in granulosa cell tumours. PLoS One. 2012;7:e46270

33. Al-Agha OM, Huwait HF, Chow C, Yang W, Senz J, Kalloger SE, Huntsman DG, Young RH, Gilks CB. FOXL2 Is a Sensitive and specific marker for sex cord-stromal tumors of the ovary. Am J Surg Pathol. 2011;35:484-94.

34. McCluggage WG1, Singh N, Kommoss S, Huntsman DG, Gilks CB. Ovarian cellular fibromas lack FOXL2 mutations: A useful diagnostic adjunct in the distinction from diffuse adult granulosa cell tumor Am J Surg Pathol. 2013;37:1450-5. 